'Escola de Agronomia, Universidade Federal de Goiás (UFG), Goiânia, GO, Brasil

${ }^{2}$ Curso de Agronomia, Faculdade Metropolitana de Anápolis (FAMA) Av. Fernando Costa, 49, Vila Jaiara St. Norte, CEP 75064-780, Anápolis, $\mathrm{GO}$, Brasil

* autor correspondente $\boldsymbol{\nabla}$ deborahlidyasales@gmail.com

\title{
Viabilidade ecônomica da irrigação por pivô central nas culturas de soja, milho e tomate
}

\author{
Economic viability of center pivot irrigation soybean, corn, \\ and tomato crops
}

José Alves Júnior ${ }^{1}$, Déborah Lídya Alves Sales²*, Rodrigo Moura Pereira²,

Walter Danilo Maradiaga Rodriguez², Derblai Casaroli', Adão Wagner Pego Evangelista'

RESUMO: A viabilidade econômica de um empreendimento agrícola com irrigação é influenciada pelos custos de implantação, manutenção e eficiência do sistema, os quais, por sua vez, variam em função das lâminas e do manejo de irrigação ao longo do ciclo. O objetivo deste estudo foi verificar a viabilidade econômica da irrigação por pivô central em cultivos de soja, milho e tomate, para diferentes demandas de evapotranspiração e consequente variação no dimensionamento hidráulico e manejo da irrigação. Para o estudo, considerou-se uma área irrigada por pivô central de 80,78 ha, simulando o cultivo rotativo de soja, milho e tomate $\left(2,5\right.$ colheitas $/$ ano $\left.^{-1}\right)$, na região de Cristalina (GO), ao longo da vida útil do sistema (30 anos). Considerou-se a ETo média histórica da região, além de outros sete valores simulados (ETo entre 4 e $7 \mathrm{~mm} / \mathrm{dia}^{-1}$ ) para dimensionamento dos projetos e manejo da irrigação. Utilizou-se a planilha AmazonSaf-Embrapa para o cálculo de indicadores financeiros em função de coeficientes técnicos de cultivo para a região. Verificou-se que, em média, $50 \%$ do custo total de produção do sistema agrícola destinam-se a fertilizantes, adubação e controle fitossanitário e apenas $8 \%$, com irrigação (4\% de investimento em equipamentos hidráulicos e barragem e 4\% referentes ao custo variável com energia). A variação de $77 \%$ na lâmina de irrigação ocasionou redução direta de apenas $2,4 \%$ no custo total de produção. Isso revela viabilidade do empreendimento, mesmo com essa variação na lâmina de irrigação, com relação benefício/custo de 2,1 e possibilidade de abater os investimentos em 2 anos, com rentabilidade (VPL) média de $\mathrm{R} \$ 6$ mil.ha $^{-1}$ ano $^{-1}$.

PALAVRAS-CHAVE: Análise financeira, custo de energia, custo de implantação, aspersão.
ABSTRACT: The economic viability of an agricultural project with irrigation is influenced by the implementation costs and system maintenance. They vary with the water capacity applied by irrigation system and the water applied in the crop cycle. The objective of this study was to verify the economic viability of irrigation center pivot on soybean, corn and tomato crops, for different evapotranspiration levels consequent variation in hydraulic design and irrigation management. An area irrigated by center pivot of 80.78 ha was considered for the study, simulating the rotary cultivation of soybeans, corn, and tomatoes (2.5 crop per year), in the region of Cristalina-GO, with useful life of irrigation system of 30 years. It was considered ETo historical average in the region, as well as seven other simulated values (ETo 4 to $7 \mathrm{~mm}$ per day). The AMAZONSAF-EMBRAPA software was used for the calculation of financial indicators based on technical coefficients of cultivation in the region. It was verified that on average $50 \%$ of the total cost of production are with fertilizers, fertilization and phytosanitary control, and only $8 \%$ with irrigation (4\% of investment with hydraulic equipment + dam and $4 \%$ cost with energy). The $77 \%$ variation in water requirement caused a reduction of only $2.4 \%$ in the total production cost. This reveals viability of the project, even with variation ETo level, with a benefit/cost ratio of 2.1 and the possibility to pay investments in 2 years, with average profitability of $R \$ 6,000 \mathrm{ha}^{-1}$ year-1.

KEYWORDS: Financial analysis, energy cost, investment cost, sprinkling.

\section{Introdução}

Um dos sistemas de irrigação mais utilizados para o cultivo de soja, milho, tomate industrial e outras culturas na região do Cerrado é o pivô central (LANDAU; GUIMARÃES; REIS, 2013). Sistema motomecanizado, caracterizado por irrigar grandes áreas, requer pouca mão de obra, apresenta facilidade 
em automação e quimigação, boa uniformidade de aplicação e facilita a sucessão de culturas por não precisar ser removido para plantio, tratos culturais nem colheita (SANDRI; CORTEZ, 2009; CARVALHO; OLIVEIRA, 2012).

A irrigação por pivô central se expandiu no Brasil nos últimos anos, mais notadamente nos estados de São Paulo, Goiás, Minas Gerais e Bahia (SANDRI; CORTEZ, 2009). Segundo dados do Instituto de Estatísticas e estudos socioeconômicos Mauro Borges para 2013, existiam 2.895 equipamentos instalados no estado de Goiás, como uma área total irrigada de 212.758 ha, o que corresponde a $0,62 \%$ do território goiano (LANDAU; GUIMARÃES; REIS, 2013).

O município de Cristalina (GO) destaca-se no setor agropecuário, em razão do sucesso da agricultura irrigada por pivô central, com mais de 600 pivôs centrais em uma área superior a 56.370 ha (INSTITUTO..., 2016). Estudos demonstraram que o número de pivôs subiu 245\% em dez anos (QUIRINO; SALES; SILVA, 2011; AGÊNCIA..., 2013).

A irrigação por pivô central na região do Cerrado é mais utilizada no período seco do ano. Durante o período de chuva, essas áreas são, normalmente, cultivadas com soja ou milho, as quais, na eventualidade de ocorrência de veranicos, podem ser irrigadas de forma complementar (SANO et al., 2005).

Apesar de a irrigação ser considerada um seguro agrícola para os produtores rurais e até mesmo uma importante ferramenta para os agricultores enfrentarem variações climáticas, como El Niño, La Niña e aquecimento global, trata-se de uma técnica cara que, se mal dimensionada e manejada, pode reduzir significativamente a rentabilidade do empreendimento, podendo inviabilizar seu uso (PEREIRA et al., 2015).

Geralmente, no desenvolvimento de projetos de irrigação, é comum tratar isoladamente as seguintes etapas: estudo de viabilidade, planejamento, dimensionamento e construção. No entanto, um projeto de irrigação, para ter um manejo racional, deve considerar todos esses aspectos de forma interligada. Dependendo de cada caso, a intenção de irrigar pode ser: a maximização da produção por unidade d'água aplicada, a maximização da produção por unidade de área ou a maximização dos lucros (FRIZZONE, 2007).

Devido ao desconhecimento ou por falta de critérios, ou pensando em reduzir exageradamente os riscos de falta de água para as plantas, muitos projetos são superdimensionados, o que implica aumento do custo de implantação e operação do sistema de irrigação.

Assim, este trabalho objetivou verificar a viabilidade econômica da irrigação por pivô central em cultivos de soja, milho e tomate, para diferentes demandas de evapotranspiração e consequente variação no dimensionamento hidráulico e manejo da irrigação.

\section{Material e Métodos}

O estudo para análise de viabilidade econômica foi desenvolvido por meio da simulação e comparação de sete projetos de pivô central, dimensionados com lâminas de irrigação de $5,65,6,34,6,42,6,71,6,96,7,06$ e $10,0 \mathrm{~mm} / \mathrm{dia}^{-1}$ e evapotranspiração de referência (ETo) de 4,00, 4,49, 4,55, 4,75, 4,93, 5,0 e 7,08 mm/dia ${ }^{-1}$
(ETo média para o período de setembro/outubro igual a $4,5 \mathrm{~mm} / \mathrm{dia}^{-1}$ para a região de Cristalina (GO) (SISTEMA..., 2014). As lâminas de projeto foram calculadas utilizando um coeficiente de cultura máximo de $\mathrm{Kc}_{\text {máx }}=1,2$ correspondente ao período de maior demanda da cultura do milho (ALLEN et al., 1998), cultura de maior demanda dentro do sistema de cultivo adotado (soja, milho e tomate industrial) e eficiência de aplicação de $85 \%$ para pivô central (BERNARDO; SOARES; MANTOVANI, 2006).

Para o cálculo da lâmina adotada no manejo de irrigação de abril a outubro (período de estiagem), utilizou-se um $\mathrm{Kc}_{\text {médio }}$ de 1,0 para as culturas de soja, milho e tomate industrial. Consideraram-se 150 dias de irrigação por ano, sendo 25 dias de irrigação em cultivo de primavera/verão (soja/milho), 25 dias de irrigação em cultivo de verão/outono (soja/milho) e 100 dias de irrigação para as culturas de inverno/primavera (tomate/milho), com ciclo médio de 120 dias. Foram consideradas 2,5 safras médias/ ano ${ }^{-1}$, com cerca de 140 dias de ocupação da terra com culturas agrícolas, diminuindo as operações de colheita e semeadura.

Após o dimensionamento hidráulico dos projetos de pivô central (para as lâminas anteriormente citadas) para a área de 80,78 ha e desnível de terreno de $2,0 \%$, analisou-se a viabilidade técnico-econômica. Os orçamentos dos projetos de irrigação dimensionados e o valor da barragem foram obtidos em estabelecimentos comerciais especializados na área de irrigação. O levantamento de dados necessários para implantação das culturas foi obtido na Federação da Agricultura e Pecuária de Goiás (FEDERAÇÃO..., 2014).

Para os cálculos de viabilidade, utilizou-se a planilha eletrônica amazonSaf(ARCO-VERDE; AMARO, 2011). Os indicadores que avaliaram a viabilidade do investimento foram indicador de lucratividade - refere-se à receita bruta $(\mathrm{RB}, \mathrm{R} \$)$, que foi determinada pela Equação 1:

$R B=P d \cdot P V$

Em que Pd é a produção na área de estudo, 80,78 ha (kg), e PV, o preço de venda (R\$); valor presente líquido (VPL) - definido como a diferença entre o valor presente dos benefícios e o valor presente dos custos (FRIZZONE; ANDRADE JÚNIOR, 2005), determinado pela Equação 2:

$V P L=\sum_{j=0}^{n} \frac{C F_{j}}{(1+i)^{j}}$

Sendo $\mathrm{n}$ o horizonte do projeto, j o período, CF o saldo do fluxo de caixa e i a taxa de juros. Para efeito de cálculo, utilizou-se uma taxa mínima de atratividade (TMA) de 4\%; taxa interna de retorno (TIR) determinada pela Equação 3 é a potencialidade do projeto de gerar retornos; quando aplicada ao cálculo da VPL, essa taxa zera o resultado (GARZEL, 2003; FRIZZONE; ANDRADE JUNIOR, 2005):

$\operatorname{TIR}=\sum_{j=0}^{n} \frac{C F_{j}}{(1+i)^{j}}=0$

A diferença entre a TIR e a TMA resulta no prêmio que o projeto está se comprometendo resultar para que o investidor aceite o risco (prêmio de risco); período de recuperação do 
capital (PRC) - também conhecido como payback period, é o tempo que o projeto leva para retornar o capital investido (NORONHA, 1987); benefício/custo (B/C) - essa razão verifica se os benefícios são maiores do que os custos. Veja a Equação 4 (FRIZZONE; ANDRADE JÚNIOR, 2005):

$B / C=\frac{\sum_{k=0}^{n} B_{k}(1+j)^{-k}}{\sum_{k=0}^{n} C_{k}(1+j)^{-k}}$

Em que B é o benefício (R\$), C, o custo (R\$), j, a taxa de juros (anual) e $\mathrm{k}$, a vida útil (anos).

Ospreçosdevendadasoja (produtividade $=4.200 \mathrm{~kg} \cdot \mathrm{ha}^{-1}$; área $=80,78 \mathrm{ha}$; preço $=\mathrm{R} \$ 0,18 \mathrm{~kg}^{-1}$ ), do milho (produtividade $=12.000 \mathrm{~kg} \cdot \mathrm{ha}^{-1}$; área $=80,78$ ha; preço $=\mathrm{R} \$ 0,25 \mathrm{~kg}^{-1}$ ) e do tomate industrial (produtividade $=85.200 \mathrm{~kg} \cdot \mathrm{ha}^{-1} ;$ área $=80,78 \mathrm{ha}$; preço $=\mathrm{R} \$ 0,95 \mathrm{~kg}^{-1}$ ) representam os valores aceitos e utilizados pela FAEG (FEDERAÇÃO..., 2014) em projeções e financiamentos. As receitas elaboradas para os fluxos de caixa resultaram das projeções da produtividade, áreas e preços. A Tabela 1 apresenta a época de colheita de soja, milho e tomate industrial, em Cristalina (GO), com média de 2,5 safras/ano ${ }^{-1}$.

\section{Resultados e Discussão}

Os resultados revelaram que em ordem crescente os custos totais de produção foram soja, milho e tomate (em Cristalina, [GO]), com $\mathrm{R} \$ 1.598,59, \mathrm{R} \$ 2.707,38$ e $\mathrm{R} \$ 7.490,36 \mathrm{ha}^{-1}$, respectivamente (Tabela 2). O custo de produção do tomate foi duas a quatro vezes maiores que o do milho e da soja, em razão dos altos custos com mudas/plantio, defensivos/pulverizações e colheita, que, juntos, representaram $76 \%$ dos custos. Já o custo do milho foi 1,7 vezes maior que o da soja, em razão do maior custo com fertilizantes/adubação $(42,5 \%$ dos custos). Resultados semelhantes foram encontrados pela FNP (FNP CONSULTORIA..., 2015).

$O$ custo médio de implantação do sistema de irrigação por pivô central (Tabela 3), para os diferentes cenários (diferentes lâminas de irrigação entre 5,65 e 10,00 mm), foi de $\mathrm{R} \$ 6.208,98 \mathrm{ha}^{-1}$. Observou-se aumento de $16,7 \%$ no custo de implantação do equipamento, passando de R 6 mil para R\$ 7 mil ha $^{-1}$. Isto ocorreu devido ao aumento na vazão de projeto $\left(217,35\right.$ para $\left.384,68 \mathrm{~m}^{3} \mathrm{~h}^{-1}\right)$, no diâmetro das tubulações dos primeiros vãos do pivô (200 para $250 \mathrm{~mm}$ ), da adutora ( 250 para $300 \mathrm{~mm}$ ), bem como da potência do conjunto moto-bomba, de 48 para $92 \mathrm{cv}$ (Tabela 3). Assim, como as culturas apresentam custos de produção distintos, o custo com a implantação da irrigação (Tabela 3), cerca de R 19 mil ha $^{-1}$ (irrigação + barragem), que foi divido igualmente para soja, milho e tomate, representou $12 \%, 7 \%$ e $2,6 \%$ dos custos totais de produção de cada cultura, respectivamente (Tabela 2).

Em relação aos custos variáveis da irrigação (energia e manutenção), estes foram mais que o dobro na cultura do tomate ( $\mathrm{R} \$ 374,50 \mathrm{ha}^{-1}$ ) em comparação com os custos do milho $\left(\mathrm{R} \$ 170,60 \mathrm{ha}^{-1}\right)$ e da soja $\left(\mathrm{R} \$ 171,00 \mathrm{ha}^{-1}\right)$, em razão da maior lâmina de irrigação $\left(400 \mathrm{a} 708 \mathrm{~mm} / \mathrm{ciclo}^{-1}\right)$ aplicada no cultivo de inverno (período de estiagem durante todo o ciclo da cultura), em comparação as menores lâminas (200 a $354 \mathrm{~mm} /$ ciclo $\left.^{-1}\right)$ aplicadas no início do ciclo na primavera e no final do ciclo no outono (Tabela 3). Da mesma maneira, como as culturas apresentaram custos de produção distintos, os custos variáveis médios representaram $10,7 \%, 6,3 \%$ e $4,5 \%$ dos custos totais de produção da soja, milho e tomate, respectivamente (Tabela 2). O aumento de $90 \%$ na potência do motor, entre os projetos dimensionados com $\mathrm{ETo}_{\text {máx }}$ de 4 para $7 \mathrm{~mm} / \mathrm{dia}^{-1}$, fez aumentar também o consumo de energia em $74 \%$ ( 43,97 para $76,45 \mathrm{kWh}$ ) e, consequentemente, seu custo tanto para as culturas de verão/outono, soja/milho, quanto para as culturas de inverno/primavera,

Tabela 1. Época do ano de colheita de soja, milho e tomate industrial em Cristalina (GO), em área de pivô central. Destaque para a média de 2,5 safras por ano, com total de 75 colheitas em 30 anos.

\begin{tabular}{|c|c|c|c|c|c|}
\hline Ano & Jan & Mar & Jun & Ago & Nov \\
\hline 1 & Soja & - & Milho & - & Milho \\
\hline 2 & - & Soja & - & Tomate & - \\
\hline 3 & Soja & - & Tomate & - & Milho \\
\hline 4 & - & Soja & - & Tomate & - \\
\hline 5 & Soja & - & Milho & - & Tomate \\
\hline 6 & - & Milho & - & Tomate & - \\
\hline 7 & Soja & - & Tomate & - & Milho \\
\hline 8 & - & Milho & - & Tomate & - \\
\hline 9 & Soja & - & Milho & - & Milho \\
\hline 10 & - & Soja & - & Tomate & - \\
\hline 11 & Soja & - & Tomate & - & Milho \\
\hline 12 & - & Soja & - & Tomate & - \\
\hline 13 & Soja & - & Milho & - & Tomate \\
\hline 14 & - & Milho & - & Tomate & - \\
\hline 15 & Soja & - & Tomate & - & Milho \\
\hline 16 & - & Soja & - & Tomate & - \\
\hline 17 & Soja & - & Milho & - & Milho \\
\hline 18 & - & Soja & - & Tomate & - \\
\hline 19 & Soja & - & Tomate & - & Milho \\
\hline 20 & - & Milho & - & Tomate & - \\
\hline 21 & Soja & - & Milho & - & Tomate \\
\hline 22 & - & Soja & - & Tomate & - \\
\hline 23 & Soja & - & Tomate & - & Milho \\
\hline 24 & - & Soja & - & Tomate & - \\
\hline 25 & Soja & - & Milho & - & Milho \\
\hline 26 & - & Milho & - & Tomate & - \\
\hline 27 & Soja & - & Tomate & - & Milho \\
\hline 28 & - & Soja & - & Tomate & - \\
\hline 29 & Soja & - & Milho & - & Milho \\
\hline 30 & - & Soja & - & Tomate & - \\
\hline
\end{tabular}

Ciclo médio de 120 dias por cultura, porém, devido ao contrato dos produtores irrigantes com as empresas de processamento de tomate e beneficiamento de grãos/sementes, ocorre atraso na colheita e, consequentemente, no plantio/semeadura da cultura sucessora, elevando para mais de 140 dias o período entre um ciclo e outro. 
Tabela 2. Porcentagem de investimentos, atividades e insumos no custo total de produção de soja, milho e tomate industrial irrigado por pivô central.

\begin{tabular}{|c|c|c|c|c|c|c|}
\hline \multirow{2}{*}{ Investimentos/atividades/insumos } & \multicolumn{2}{|c|}{ Soja } & \multicolumn{2}{|c|}{ Milho } & \multicolumn{2}{|c|}{ Tomate } \\
\hline & R\$ ha-1 & $\%$ & R\$ ha $\mathbf{~ h}^{-1}$ & $\%$ & R\$ ha' ${ }^{-1}$ & $\%$ \\
\hline Custo de produção total & 1598,59 & $100 \%$ & 2707,38 & $100 \%$ & 7490,36 & $100 \%$ \\
\hline Irrigação (implantação) & 191,80 & $12 \%$ & 189,50 & $7 \%$ & 194,70 & $2,6 \%$ \\
\hline Irrigação (energia) & 171,00 & $10,7 \%$ & 170,60 & $6,3 \%$ & $\mathbf{3 7 4 , 5 0}$ & $4,5 \%$ \\
\hline Colheita (operação) & 175,80 & $11 \%$ & 189,50 & $7 \%$ & 2621,60 & $35 \%$ \\
\hline Aplicação de defensivos & 159,90 & $10 \%$ & 411,50 & $15,2 \%$ & $\mathbf{3 7 4 , 5 0}$ & $5 \%$ \\
\hline Semeadura/plantio & 79,90 & $5 \%$ & 43,30 & $1,6 \%$ & 149,80 & $1,9 \%$ \\
\hline Adubação & 24,00 & $1,5 \%$ & 81,20 & $3 \%$ & 52,40 & $0,6 \%$ \\
\hline Sementes/mudas & 119,90 & $7,5 \%$ & 243,70 & $9 \%$ & 1423,20 & $19 \%$ \\
\hline Fertilizantes & 255,80 & $16 \%$ & 1069,40 & $39,5 \%$ & 1198,50 & $16 \%$ \\
\hline Defensivos & 383,70 & $24 \%$ & 284,30 & $10,5 \%$ & 1123,60 & $15 \%$ \\
\hline Outros & 36,00 & $2,3 \%$ & 24,40 & $0,9 \%$ & 30,00 & $0,4 \%$ \\
\hline
\end{tabular}

Tabela 3. Variação nos custos de implantação e operação de sete projetos de pivô central dimensionados e operados com evapotranspiração de referência (ETo) variando de 4 a $7 \mathrm{~mm} /$ dia, para soja, milho e tomate industrial ( 80,78 ha) em rotação em Cristalina (GO), por 30 anos.

\begin{tabular}{|c|c|c|c|c|c|c|c|c|}
\hline \multirow[b]{2}{*}{ Projetos } & \multirow{2}{*}{$\begin{array}{c}\text { ETo } \\
\left(\mathrm{mm} / \mathrm{dia}^{-1}\right)\end{array}$} & \multirow{2}{*}{$\begin{array}{l}\text { Moto-bomba } \\
\text { (CV) }\end{array}$} & \multicolumn{2}{|c|}{ Lâmina de irrigação $\left(\mathrm{mm} /\right.$ ciclo $\left.^{-1}\right)$} & \multicolumn{2}{|c|}{$\begin{array}{l}\text { Tempo de bombeamento } \\
\left(\mathrm{h} / \text { ciclo }^{-1}\right)\end{array}$} & \multicolumn{2}{|c|}{ Avaliação financeira } \\
\hline & & & $\begin{array}{c}\text { Soja/milho } \\
\text { (verão/outono) }\end{array}$ & $\begin{array}{c}\text { Tomate/milho } \\
\text { (inverno/primavera) }\end{array}$ & $\begin{array}{c}\text { Soja/milho } \\
\text { (verão/ } \\
\text { outono) }\end{array}$ & $\begin{array}{c}\text { Tomate/milho } \\
\text { (inverno/ } \\
\text { primavera) }\end{array}$ & \multicolumn{2}{|c|}{ (Soja/milho/tomate) } \\
\hline 1 & 4,00 & 48,65 & 200 & 400 & 743 & 1486 & $\begin{array}{c}\text { TMA } \\
\text { (juros) \% }\end{array}$ & $4 \%$ \\
\hline 2 & 4,49 & 58,73 & 225 & 449 & 744 & 1487 & $\begin{array}{l}\text { TIR do } \\
\text { projeto }\end{array}$ & $250 \%$ \\
\hline 3 & 4,55 & 59,87 & 228 & 455 & 744 & 1488 & $\begin{array}{l}\text { Payback } \\
\text { (anos) }\end{array}$ & 2,0 \\
\hline 4 & 4,75 & 61,32 & 238 & 475 & 743 & 1487 & B/C (R\$) & 2,1 \\
\hline 5 & 4,93 & 66,09 & 247 & 493 & 744 & 1488 & - & - \\
\hline 6 & 5,00 & 67,34 & 250 & 500 & 744 & 1488 & - & - \\
\hline \multirow[t]{3}{*}{7} & 7,08 & 92,34 & 354 & 708 & 744 & 1487 & - & - \\
\hline & \multirow{2}{*}{$\begin{array}{l}\text { Lâmina } \\
\text { de projeto } \\
\text { (mm) }\end{array}$} & \multirow{2}{*}{$\begin{array}{c}\text { Energia } \\
\text { pivô + Mb } \\
(\mathbf{k W h})\end{array}$} & \multicolumn{2}{|c|}{ Consumo de energia $\left(\mathrm{kWh} /\right.$ ciclo $\left.^{-1}\right)$} & \multicolumn{2}{|c|}{$\begin{array}{c}\text { Custo (R\$) de energia } \\
\text { ha }^{-1} / \text { ciclo }^{-1}\end{array}$} & \multicolumn{2}{|c|}{ Aumento no custo (\%) } \\
\hline & & & $\begin{array}{c}\text { Soja/milho } \\
\text { (verão/outono) }\end{array}$ & $\begin{array}{c}\text { Tomate/milho } \\
\text { (inverno/primavera) }\end{array}$ & $\begin{array}{l}\text { Soja/milho } \\
\text { (verão/ } \\
\text { outono) }\end{array}$ & $\begin{array}{c}\text { Tomate/milho } \\
\text { (inverno/ } \\
\text { primavera) }\end{array}$ & Energia & Implantação \\
\hline 1 & 5,65 & 43,97 & 32678 & 65357 & 84,95 & 169,90 & $\mathbf{0}$ & $\mathbf{0 , 0}$ \\
\hline 2 & 6,34 & 51,46 & 38267 & 76534 & 99,48 & 198,96 & 17 & 0,9 \\
\hline 3 & 6,42 & 52,31 & 38926 & 77851 & 101,19 & 202,39 & 19 & 0,9 \\
\hline 4 & 6,71 & 53,39 & 39682 & 79364 & 103,16 & 206,32 & 21 & 0,9 \\
\hline 5 & 6,96 & 56,94 & 42371 & 84742 & 110,15 & 220,30 & 30 & 1,4 \\
\hline 6 & 7,06 & 57,87 & 43060 & 86119 & 111,94 & 223,88 & 32 & 1,6 \\
\hline 7 & 10,00 & 76,45 & 56842 & 113684 & 147,77 & 295,54 & 74 & 16,3 \\
\hline
\end{tabular}

Projetos dimensionados para funcionamento $21 \mathrm{~h}$ /dia; área de 80,78 ha. Os projetos de 1 a 6: são constituídos 1 vão inicial e 7 vãos intermediários de 8 " de diâmetro e 6 tubos, e 4 vãos de $65 / 8$ " e 6 tubos, e 1 lance em balanço de 2 tubos. O projeto $7: 1$ vão inicial e outros 5 vãos intermediários de 10 ", 4 vãos de 8 " e 2 vãos de 6 5/8", todos com 6 tubos, e 1 lance em balanço de 2 tubos. Adutora de PVC de 576 m (96 barras de 6 metros) de comprimento, para os projetos 1 a 6, 300 m (50 barras, DN 250 PN80) e o restante, 276 m (46 barras, DN 250 PN60), e para o projeto 7, 300 m (DN 300 PN80) e 276 m (DN 300 PN60). Foi considerado um valor de R\$ 1 milhão para construção da barragem. Tempo mínimo para completar uma volta é de 12,56 h. Considerou-se o valor médio de R\$ 0,21/KWh para milho, soja e tomate industrial. Foram considerados 120 dias de ciclo, 2,5 ciclos por ano, e para o cálculo da lâmina de irrigação aplicada por ciclo, considerou-se Kc médio de 1,0, e número de dias de irrigação, sendo 50 dias para as safras com colheitas no verão/outono (milho e soja) e 100 dias de irrigação com colheitas no inverno/primavera (tomate e milho). Para o custo de produção e coeficientes técnicos das culturas avaliadas, foram consideradas as planilhas divulgas pela FAEG em 2014 (FEDERAÇÃO..., 2014). 
Tabela 3. Continuação...

\begin{tabular}{|c|c|c|c|c|c|c|c|c|c|c|}
\hline & \multirow{2}{*}{$\begin{array}{l}\text { Lâmina } \\
(\mathbf{m m}) \\
\text { mínima / } \\
\text { volta }\end{array}$} & \multirow{2}{*}{$\begin{array}{c}\text { VPL } \\
\text { R\$ ha } \\
\text {-1/ano-1 }\end{array}$} & \multicolumn{3}{|c|}{ Custo (R\$) total de produção $\mathrm{ha}^{-1} /$ ciclo $^{-1}$} & \multicolumn{4}{|c|}{$\begin{array}{c}\text { Custo com barragem + irrigação + energia } \\
\text { no custo total }(\%)\end{array}$} & \multirow{2}{*}{$\begin{array}{r}\text { Energia (\%) } \\
\text { Custo total }\end{array}$} \\
\hline & & & Milho & Soja & Tomate & Milho & Soja & Tomate & Total (\%) & \\
\hline 1 & 3,38 & $6.070,13$ & $2.536,98$ & $1.525,92$ & $6.795,60$ & 10 & 16 & 5 & 8 & 3 \\
\hline 2 & 3,79 & $6.037,89$ & $2.553,08$ & $1.542,70$ & $6.827,80$ & 10 & 17 & 5 & 8 & 4 \\
\hline 3 & 3,84 & $6.034,10$ & $2.653,45$ & $1.544,68$ & $7.108,25$ & 10 & 17 & 5 & 8 & 4 \\
\hline 4 & 4,01 & $6.029,74$ & $2.655,72$ & $1.546,94$ & $7.112,79$ & 10 & 17 & 5 & 8 & 4 \\
\hline 5 & 4,16 & $6.014,37$ & $2.663,72$ & $1.554,94$ & $7.403,22$ & 10 & 18 & 5 & 8 & 4 \\
\hline 6 & 4,22 & $6.010,25$ & $2.663,73$ & $1.554,95$ & $7.403,22$ & 10 & 18 & 5 & 8 & 4 \\
\hline \multirow[t]{2}{*}{7} & 5,98 & $5.930,40$ & $2.663,89$ & $1.555,11$ & $7.403,39$ & 12 & 20 & 6 & 9 & 5 \\
\hline & \multicolumn{3}{|c|}{$\begin{array}{c}\text { Custo de implantação do sistema de } \\
\text { irrigação } \\
\left(\mathrm{RS} \mathrm{ha}^{-1}\right)\end{array}$} & \multicolumn{3}{|c|}{$\begin{array}{l}\text { Diâmetro da tubulação da adutora } \\
\qquad(\mathrm{mm})\end{array}$} & \multicolumn{2}{|c|}{$\begin{array}{c}\text { Diâmetro da } \\
\text { tubulação do pivô } \\
(\mathbf{m m})\end{array}$} & \multicolumn{2}{|c|}{$\begin{array}{l}\text { Vazão de projeto } \\
\qquad\left(\mathrm{m}^{3} \mathrm{~h}^{-1}\right)\end{array}$} \\
\hline 1 & \multicolumn{3}{|c|}{6019,06} & \multicolumn{3}{|c|}{250} & \multicolumn{2}{|c|}{200} & \multicolumn{2}{|c|}{217,35} \\
\hline 2 & \multicolumn{3}{|c|}{6072,01} & \multicolumn{3}{|c|}{250} & \multicolumn{2}{|c|}{200} & \multicolumn{2}{|c|}{243,89} \\
\hline 3 & \multicolumn{3}{|c|}{6072,01} & \multicolumn{3}{|c|}{250} & \multicolumn{2}{|c|}{200} & \multicolumn{2}{|c|}{246,97} \\
\hline 4 & \multicolumn{3}{|c|}{6066,31} & \multicolumn{3}{|c|}{250} & \multicolumn{2}{|c|}{200} & \multicolumn{2}{|c|}{258,12} \\
\hline 5 & \multicolumn{3}{|c|}{6093,45} & \multicolumn{3}{|c|}{250} & \multicolumn{2}{|c|}{200} & \multicolumn{2}{|c|}{267,74} \\
\hline 6 & \multicolumn{3}{|c|}{6116,07} & \multicolumn{3}{|c|}{250} & \multicolumn{2}{|c|}{200} & \multicolumn{2}{|c|}{271,59} \\
\hline 7 & \multicolumn{3}{|c|}{7023,98} & & 300 & & & & & 84,68 \\
\hline
\end{tabular}

Projetos dimensionados para funcionamento 21 h/dia; área de 80,78 ha. Os projetos de 1 a 6: são constituídos 1 vão inicial e 7 vãos intermediários de 8 " de diâmetro e 6 tubos, e 4 vãos de $65 / 8$ " e 6 tubos, e 1 lance em balanço de 2 tubos. O projeto 7: 1 vão inicial e outros 5 vãos intermediários de 10", 4 vãos de 8 " e 2 vãos de $65 / 8$ ", todos com 6 tubos, e 1 lance em balanço de 2 tubos. Adutora de PVC de 576 m (96 barras de 6 metros) de comprimento, para os projetos 1 a $6,300 \mathrm{~m}$ (50 barras, DN 250 PN80) e o restante, $276 \mathrm{~m}$ (46 barras, DN 250 PN60), e para o projeto 7, $300 \mathrm{~m}$ (DN 300 PN80) e $276 \mathrm{~m}$ (DN 300 PN60). Foi considerado um valor de R\$ 1 milhão para construção da barragem. Tempo mínimo para completar uma volta é de 12,56 h. Considerou-se o valor médio de R\$ 0,21/KWh para milho, soja e tomate industrial. Foram considerados 120 dias de ciclo, 2,5 ciclos por ano, e para o cálculo da lâmina de irrigação aplicada por ciclo, considerou-se Kc médio de 1,0, e número de dias de irrigação, sendo 50 dias para as safras com colheitas no verão/outono (milho e soja) e 100 dias de irrigação com colheitas no inverno/primavera (tomate e milho). Para o custo de produção e coeficientes técnicos das culturas avaliadas, foram consideradas as planilhas divulgas pela FAEG em 2014 (FEDERAÇÃO..., 2014).

tomate/milho (R\$ 84,95 para $\mathrm{R} \$ 147,77 \mathrm{ha}^{-1}$ ciclo $^{-1} ; \mathrm{R} \$ 169,90$ para $295,54 \mathrm{ha}^{-1}$ ciclo $^{-1}$, respectivamente).

De maneira geral, observa-se (Tabela 2) que, em média, $50 \%$ do custo total de produção do sistema agrícola soja, milho e tomate industrial destina-se a fertilizantes, adubação e controle fitossanitário, e apenas $8 \%$, à irrigação (4\% de investimento com equipamentos hidráulicos e barragem e $4 \%$ referentes ao custo variável com energia). Entretanto, apesar de a irrigação representar pouco no custo de produção desse sistema agrícola, tem relação indireta com o alto custo com fertilizantes e defensivos, pois o excesso de água aplicado proporciona lixiviação de nitrato e potássio, elevando os custos com adubação e/ou quebra de produtividade. Também, em geral, teores elevados de água no solo, saturação, favorecem os microrganismos patogênicos (GROGAN; ABAWI, 1975; MORRALL, 1977; FENILLE; SOUZA, 1999; MAROUELLI et al., 2005; CARRER FILHO et al., 2009). Alguns estudos revelam (NAPOLEÃO et al., 2005, 2007) que o uso de plantio direto na palha ajuda a controlar algumas doenças, como o mofo branco, que, além de umidade, necessita de luz para frutificar. Entretanto, muitos irrigantes aplicam lâmina de irrigação de plantio convencional em área de plantio direto palhada reduz a evapotranspiração (PAVANI; LOPES; GALBEIRO, 2008), e esse excesso de água pouco afeta os custos com energia elétrica, como mostrado neste estudo (Tabela 3), mas pode proporcionar lixiviação e maior incidência de doenças, aumentando também os custos de produção indiretamente.
Dessa maneira, os resultados mostram que mesmo com uma grande variação nos valores de ETo, entre 4,0 e 7,0 mm/ dia $^{-1}$, para dimensionamento de projeto hidráulico e manejo da irrigação, isso ocasionou redução direta de apenas $2,4 \%$ no custo total de produção. Tal fato revela viabilidade do empreendimento, mesmo que ocorra erro nas lâminas de projeto e de manejo da irrigação, com rentabilidade (VPL) média de R 6 mil ha ${ }^{-1} / \mathrm{ano}^{-1}$. Esses resultados estão de acordo com os relatados por Mello (2004).

Para os sete cenários aliados, verificou-se lucro, B/C $>1,0$ (GARZEL, 2003), pois o valor médio de benefício/custo foi igual a $\mathrm{R} \$ 2,10$. O resultado acumulativo permitiu calcular o período de retorno do capital investido em dois anos (período de amortização do investimento) e a taxa interna de retorno (TIR) com mais de $200 \%$. Para um período de 30 anos, o produtor consegue abater os custos de implantação em dois anos, com relação benefício/custo de 2,1.

\section{Conclusão}

A implantação de um sistema de irrigação por pivô central é viável para o cultivo de soja, milho e tomate industrial, nas condições edafoclimáticas do Cerrado goiano.

O aumento da evapotranspiração de referência ocasiona maior custo de implantação e manutenção do pivô central. 


\section{Referências}

AGÊNCIA NACIONAL DE ÁGUAS - ANA. Subsídios para a discussão da compatibilização da geração de energia hidrelétrica com expansão da agricultura irrigada na bacia do rio São Marcos. Brasília: ANA, 2013.

ALLEN, R. G. et al. Crop evapotranspiration: Guidelines for computing crop water requirements. Rome: FAO, 1998. 300 p. (FAO - Irrigation and Drainage Paper, 56).

ARCO-VERDE, M. F.; AMARO, G. Cálculo de indicadores financeiros para sistemas agroflorestais. Roraima: Embrapa Roraima, 2011. p. 48. (Documentos, 44).

BERNARDO, S.; SOARES, A. A.; MANTOVAnI, E. C. Manual de irrigação. 8. ed. Viçosa: UFV, 2006.

CARRER FILHO, R. et al. Potencialidade de um actinomiceto de rizosfera de tomateiro como agente de biocontrole de doenças. Horticultura Brasileira, Brasília v. 27, n. 3, p. 340-344, 2009.

CARVALHO, D. F.; OLIVEIRA, L. F. C. Planejamento e manejo da água na agricultura irrigada. Viçosa: Editora UFV, 2012. v. 1. $240 \mathrm{p}$.

FEDERAÇÃO DA AGRICULTURA E PECUÁRIA DE GOIÁS FAEG. Index: sistemas de cotações. 2014. Disponível em: $<$ http:// sistemafaeg.com.br/mercados-e-cotacoes/milho $>$. Acesso em: 10 nov. 2014

FENILLE, R. C.; SOUZA, N. L. Efeitos de materiais orgânicos e da umidade do solo na patogenicidade de Rhizoctoniasolanikühn GA-4 HGI ao feijoeiro. Pesquisa Agropecuária Brasileira, Brasília, v. 34, n. 10, p. 1959-1967, 1999

FNP CONSULTORIA E INFORMAÇÕES EM AGRONEGÓRCIO. Soja - Agrianual 2015: Anuário da Agricultura Brasileira. São Paulo, 2015. p. 409-444.

FRIZZONE, J. A. Planejamento da irrigação com uso de técnicas de otimização. Revista Brasileira de Agricultura Irrigada, Fortaleza, v.1, n. 1, p. 24-49, 2007

FRIZZONE, J. A.; ANDRADE JÚNIOR, A. S. Planejamento de irrigação: análise de decisão de investimento. Brasília: Embrapa Informação Tecnológica, 2005. p. 626.

GARZEL, J. C. Matemática financeira e análise de investimentos. Curitiba: SENAR-PR, 2003. p. 37.

GROGAN, R. G.; ABAWI, G. S. Influence of water potencial on growth and survival of Whetzeliniasclerotiorum. Phytopathology, Mineaussota, v. 65, p. 122-138, 1975.

INSTITUTO BRASILEIRO DE GEOGRAFIA E ESTATÍSTICA-IBGE. Goiás - Cristalina. 2016. Disponível em: $<$ http://cidades.ibge.gov. $\mathrm{br} / \mathrm{xtras} /$ temas.php?lang=\& codmun $=520620 \&$ idtema $=16 \&$ search $=$ goias|cristalina|sintese-das-informacoes>. Acesso em: 5 set. 2014.

LANDAU, E. C.; GUIMARÃES, D. P.; REIS, R. J. Index: mapeamento das áreas irrigadas por pivôs centrais no Estado de Goiás e no Distrito
Federal. Boletim de Pesquisa, n. 77, p. 8, 2013. Disponível em: $<$ http://http://ainfo.cnptia.embrapa.br/digital/bitstream/item/94389/1/ bol-77.pdf $>$. Acesso em: 6 out. 2014

MAROUELLI, W. A.; LOPES, C. A.; SILVA, W. L. C. Incidência de murcha-bacteriana em tomate para processamento industrial sob irrigação por gotejamento e aspersão. Horticultura Brasileira, Brasília, v. 23, n. 2, p. 320-323, 2005.

MELLO, L. M. M. Integração lavoura-pecuária e irrigação. Irrigaterra Informe - Irrigação Favorece a Lucratividade, Pereira Barreto, v. 1, n. 2, p. 3-4, 2004.

MORRALL, R. A. A. A preliminary study of the influence of water potential on sclerotium germination in Sclerotiniasclerotiorum. Canadian Journal of Botany, v. 55, p. 1-11, 1977.

NAPOLEÃO, R. et al. Intensidade do mofo-branco do feijoeiro em plantio convencional e direto sob diferentes lâminas d'água. Fitopatolia Brasileira, Brasília, v. 30, n. 4, 2005.

NAPOLEÃO, R. et al. Efeito da frequência de rega e da umidade do solo sobre a germinação carpogênica de sclerotinia sclerotiorum. Summa phytopathológica, Botucatu, v. 33, n. 1, p. 80-82, 2007.

NORONHA, J. F. Projetos agropecuários: administração financeira, orçamento eviabilidade econômica. 2. ed. São Paulo: Atlas, 1987. p. 269.

PAVANI, L. C.; LOPES, A. S.; GALBEIRO, R. B. Manejo da irrigação na cultura do feijoeiro em sistemas plantio direto e convencional. Engenharia Agrícola, Jaboticabal, v. 28, n. 1, p. 12-21, 2008.

PEREIRA, R. M. et al. Viabilidade econômica da irrigação de cana-de-açúcar no cerrado brasileiro. Irriga, Botucatu, p. 149-157, 2015. Edição Especial.

QUIRINO, D. T.; SALES, L. F. P.; SILVA, O. F. (2011). Aplicação do sensoriamento remoto para análise temporal em agriculturas irrigadas por pivô central no município de Cristalina GO. In: SIMPÓSIO BRASILEIRO DE SENSORIAMENTO REMOTO, 15., 2011. Curitiba. Anais... Curitiba: Organização INPE, 2011. p. 154-160.

SANDRI, D.; CORTEZ, D. Parâmetros de desempenho de dezesseis equipamentos de irrigação por pivô central. Ciência e Agrotecnologia, Lavras, v. 33, n. 1, p. 271-278, 2009.

SANO, E. E. et al. Estimativa da variação na demanda de água para irrigação por pivô central no Distrito Federal entre 1992 e 2002. Engenharia Agrícola, Jaboticabal, v. 25, n. 2, p. 508-515, 2005.

SISTEMA DE METEOROLOGIA E HIDROLOGIA ESTADO DE GOIÁS - SIMEHGO. Sistema de Meteorologia e Hidrogeologia do estado de Goiás. 2014. Disponível em: <http://www.simehgo. sectec.go.gov.br/agro/index.php>. Acesso em: 20 set. 2014.

Recebido: 12 mar. 2015 Aprovado: 18 set. 2017 